LETTERS

\section{Tobacco use among school personnel in Bihar, India}

Tobacco use often starts in adolescent years when school personnel form important role models, potentially influencing tobacco use. To plan effective interventions, it is essential to have information on the extent and the type of tobacco use among school personnel, their attitudes towards tobacco control, and the existence of school health polices about tobacco.

Tobacco use among 13-15 year old students is being studied worldwide through the Global Youth Tobacco Survey (GYTS) ${ }^{2}$ which incorporates the Global School Personnel Survey (GSPS). The objectives of GSPS are: (1) obtain baseline information on tobacco use; (2) evaluate the existence, implementation, and enforcement of tobacco control policies in schools; (3) understand the knowledge and attitudes towards tobacco control policies; (4) assess training and material requirements for implementing tobacco prevention and control interventions; and (5) verify some information obtained from the GYTS. The GSPS was piloted in the state of Bihar, India and this report presents the results from the first pilot of GSPS.

GSPS is a cross sectional survey that employs a cluster sample design to produce a representative sample of school personnel drawn from the same schools that were selected for GYTS. For GYTS, schools were sampled with probability of selection proportional to the school enrolment size in grades 8-10 (corresponding to ages $13-15$ years). A total of 50 schools out of 9905 listed for Bihar state were sampled. All school personnel (including all non-teaching staff) in the selected schools were eligible to participate. In India, education is a state responsibility and almost all schools were part of Bihar state educational system.

Bihar GSPS was conducted in the month of September and October 2000 using the same survey personnel who had conducted GYTS. The questionnaire contained 46 multiple choice questions. Survey procedures allowed for anonymous and voluntary participation. School personnel completed the self administered questionnaire during the break hours, recording their responses directly on a sheet which could subsequently be optically read by machine. The data file obtained was analysed using Epi Info. This software took the sampling weights into account for producing unbiased estimates of proportions and confidence intervals.

All selected schools participated in the survey (response rate $100 \%$ ). Selected schools reported having a total of 697 eligible personnel, out of which 637 returned the completed questionnaire. The main reason for nonresponse was absence from school on the day of the survey. The school personnel response rate was $91.4 \%$.

Out of 637 participating school personnel $73 \%$ were men. Some $22.5 \%$ were less than 40 years old and $38.6 \%$ were 50 years or older Very few were more than 60 as mandatory retirement age is 60 years. Women were

Table 1 Prevalence of tobacco use among school personnel in Bihar by sex-Bihar GSPS 2000

\begin{tabular}{llll}
\hline & Male (\%) & Female (\%) & Total (\%) \\
\hline Total number & 502 & 128 & 630 \\
Any tobacco & $77.6(7.8)$ & $77.0(14.3)$ & $77.4(7.7)$ \\
Smokeless & $58.7(6.3)$ & $53.4(16.1)$ & $57.3(7.5)$ \\
Smoking & $47.4(8.7)$ & $31.0(8.9)$ & $43.0(7.1)$ \\
Cigarette & $40.5(5.9)$ & $26.9(9.9)$ & $36.8(5.0)$ \\
Others* & $17.4(4.6)$ & $4.3(4.7)$ & $13.9(3.5)$ \\
\hline
\end{tabular}

Figures in parentheses denotes confidence intervals $( \pm \mathrm{Cl})$.

${ }^{*}$ Mostly bidi

somewhat younger than men. The majority of school personnel $(83.5 \%)$ were teachers and there were only two health personnel.

Table I shows tobacco use prevalence among school personnel. Some $77.4 \%$ reported using tobacco in one form or the other The prevalence was almost identical among men $(77.6 \%)$ and women $(77.0 \%)$. There was little difference in smokeless tobacco use among men $(58.7 \%)$ and women $(53.4 \%)$. Although smoking among women in India is generally proscribed, prevalence of smoking among women in this sample was quite high $(31 \%)$. Most of it was cigarette smoking (26.9\%). Among men, overall smoking prevalence was $47.4 \%$, and cigarette smoking $40.5 \%$. It should be noted that prevalence of cigarette smoking and other smoking habits do not add up to the prevalence of smoking, and prevalence of smoking and smokeless tobacco use do not add up to prevalence of tobacco use. This is because many individuals reported using tobacco in multiple forms.

Almost all school personnel (91\%) agreed that tobacco was addictive, and $85 \%$ admitted that it had serious health consequences. While $92 \%$ of never users of tobacco believed that environmental tobacco smoke (ETS) was harmful to people who were repeatedly exposed to it, $83 \%$ of current tobacco users agreed with that statement. While $83 \%$ of never tobacco users complained that ETS was a nuisance, only slightly fewer (77\%) current tobacco users did so.

Except for two people, everyone replied that there was no policy on tobacco use either for students or personnel. Even though tobacco use among school personnel was high, a vast majority was concerned about youth tobacco use $(84.7 \%)$. A large proportion $(90.4 \%)$ wanted a policy prohibiting tobacco use by students and, surprisingly, even more wanted a policy prohibiting tobacco use among school personnel $(93.9 \%)$.

Another striking finding was that $80 \%$ thought that tobacco companies deliberately encourage youth to use tobacco. Some $88.3 \%$ wanted tobacco companies not to sponsor sports events and $95 \%$ wanted a complete ban on tobacco advertisements. Surprisingly, even though a majority were tobacco users, 78.4\% agreed with the need to increase prices of tobacco products, with no difference between users and non-users.

The GSPS study findings reveal an alarming picture of very high tobacco use among schoo personnel, and a total absence of any tobacco control policy in schools administered by the state government in Bihar. The results dispel the myth of smoking as taboo among middle class women in India in so far as self administered, anonymous questionnaires revealed $31 \%$ of female school personnel reported current smoking and $26.9 \%$ reported smoking cigarettes. This social change is likely to be due to several factors such as female emancipation and role modelling from western media. The role of marketing strategies by cigarette companies however, cannot be underestimated. Almost all cigarette advertising imagery includes women, and a cigarette brand specially targeted at women with the name "Ms" is available on the market. This kind of cigarette smoking is still practised away from public view-unlike hukka (hubble bubble) and cheroot smoking by rural women-but clearly it may not remain so for long.

The findings, however, do present an encouraging picture of widespread and near total support towards the formulation and implementation of effective tobacco control policy measures.

School of Preventive Oncology, Patna, India

P C Gupta

M S Pednekar

Tata Institute of Fundamental Research, Mumbai,

India

J T Jones

Department of Non-communicable Diseases and Health Promotion, World Health Organization, Geneva, Switzerland

C W Warren

Office on Smoking and Health, Centers for Disease Control and Prevention, Bethesda, Maryland, USA

Correspondence to: Prakash C. Gupta, Tata Institute of Fundamental Research, Homi Bhabha Road, Colaba, Mumbai 400005 , India; pcgupta@tifr.res.in

\section{Acknowledgements}

The Department of Non-communicable Diseases and Health Promotion, World Health Organisation, funded this study. Authors wish to acknowledge the contribution and help from Samira Asma, Lawerence Green, Laura Kann and Leanne Riley.

\section{References}

1 World Health Organization. WHO Information series on school health; tobacco use prevention: an important entry point for the development of health-promoting schools. Geneva: WHO, 1998:13-14. 
2 Warren CW, Riley L, Asma S, et al. Tobacco use by youth: a surveillance report from the GYTS project. Bull WHO 2000;78:868-74.

\section{Exposure to environmental tobacco smoke in public places in Barcelona, Spain}

Exposure to environmental tobacco smoke (ETS) has adverse health effects for both children and adults. ${ }^{1-3}$ Southern European countries have not had the same level of ETS control measures as other western countries. The purpose of this study was to assess current ETS exposure in several locations in Barcelona, Spain.

We collected airborne nicotine with 31 diffusion monitors containing sodium bisulfate coated filters. ${ }^{45}$ Between September 1999 and March 2000 different locations were chosen from among the following 18 sites in Barcelona: five underground (subway) stations ( $\mathrm{n}=5$, one measurement in each station); two restaurants $(n=3$, one of the restaurants, located in one of the two teaching hospitals referred to below, had measurements taken from smoking and non-smoking areas); two large stores $(\mathrm{n}=4$, two measurements in each store); two teaching hospitals ( $\mathrm{n}=4$, two measurements from newborns inpatients and paediatrics outpatients departments from one hospital, and two from emergency rooms and radiography emergency departments from the other hospital); one medical schoo $(n=5)$, one official language school $(n=2)$; one secondary school $(\mathrm{n}=1)$; one general practice $(\mathrm{n}=2)$; one public health centre $(\mathrm{n}=1)$; and three households $(\mathrm{n}=4$, one smoker's home and two non-smoker's households). Nicotine concentrations for the three field blanks all corresponded to airborne concentrations of less than $0.02 \mu \mathrm{g} / \mathrm{m}^{3}$.

Monitors were left exposed for periods ranging from 7-13 days, since a minimum period of seven days was required to have a valid measure with passive monitors. One trained investigator completed a standard form with data concerning the date and time, placement and removal, exposure area, ventilation and distribution patterns, and distance from the person smoking nearby. The highest air nicotine concentration was found in restaurants, showing a mean of $12.4 \mu \mathrm{g} / \mathrm{m}^{3}$ $\left(10.6-15.0 \mu \mathrm{g} / \mathrm{m}^{3}\right)$. The air nicotine concentrations in a secondary school and in a smoker's household were $9.5 \mu \mathrm{g} / \mathrm{m}^{3}$ and $7.9 \mu \mathrm{g} / \mathrm{m}^{3}$, respectively. In department stores, the average air nicotine concentration was $2.8 \mu \mathrm{g} / \mathrm{m}^{3}$ (range $0.4-6.2 \mu \mathrm{g} / \mathrm{m}^{3}$ ). ETS exposure in the language school showed a mean nicotine concentration of $2.3 \mu \mathrm{g} / \mathrm{m}^{3}$ (range $1.7-3.0 \mu \mathrm{g} / \mathrm{m}^{3}$ ). Other results are presented in table 1 .

Although these results need to be interpreted within the limitation of having only 31 measurements and a non-random sample this is the first attempt to obtain an objective measure of ETS exposure in public places in Barcelona. The data may also provide at least an initial insight into the situation in other southern European countries where measurements of ETS exposure are not common. Res taurants showed high concentrations, includ ing two measurements obtained from hospital canteens where the average nicotine concentrations showed no significant difference between smoking and non-smoking areas ( 15.0 and $11.5 \mu \mathrm{g} / \mathrm{m}^{3}$, respectively). This may reflect a lack of compliance or a weak physical separation between the two areas, and is especially serious since it involves hos pitals. Nicotine concentrations in restaurants

Table 1 Concentrations of nicotine recorded in public places in the city of Barcelona

\begin{tabular}{|c|c|c|}
\hline Locations & $\begin{array}{l}\text { Sampling time } \\
\text { (days)* }\end{array}$ & $\begin{array}{l}\text { Nicotine concentration } \\
\left(\mu \mathrm{g} / \mathrm{m}^{2}\right)\end{array}$ \\
\hline $\begin{array}{l}\text { Underground (subway) stations (mean) } \\
\text { Platform } \\
\text { Connection } 1 \dagger \\
\text { Connection } 2 \\
\text { Connection } 3 \\
\text { Coach }\end{array}$ & $\begin{array}{r}7 \\
7 \\
7 \\
7 \\
12\end{array}$ & $\begin{array}{l}2.2 \\
0.1 \\
3.8 \\
2.1 \\
4.1 \\
1.0\end{array}$ \\
\hline $\begin{array}{l}\text { Restaurants (mean) } \\
\text { Main dining room (no division) } \\
\text { Hospital A canteen (non-smoking area) } \\
\text { Hospital A canteen (smoking area) }\end{array}$ & $\begin{array}{l}7 \\
7 \\
7\end{array}$ & $\begin{array}{l}12.4 \\
10.6 \\
11.5 \\
15.0\end{array}$ \\
\hline $\begin{array}{l}\text { Large stores (mean) } \\
\text { Store A, floor } 1 \\
\text { Store A, floor } 2 \\
\text { Store B, information centre } \\
\text { Store B, hall }\end{array}$ & $\begin{array}{r}7 \\
7 \\
13 \\
13\end{array}$ & $\begin{array}{l}2.8 \\
0.7 \\
0.4 \\
6.2 \\
3.9\end{array}$ \\
\hline $\begin{array}{l}\text { Medical school (mean) } \\
\text { Corridor } 1 \\
\text { Corridor } 2 \\
\text { Classroom } \\
\text { Cafeteria } \\
\text { Hall }\end{array}$ & $\begin{array}{l}7 \\
7 \\
7 \\
7 \\
7\end{array}$ & $\begin{array}{l}0.9 \\
2.1 \\
0.0 \\
0.1 \\
2.0 \\
0.2\end{array}$ \\
\hline $\begin{array}{l}\text { Language school (mean) } \\
\text { Hall } 1 \\
\text { Hall } 2\end{array}$ & $\begin{array}{l}7 \\
7\end{array}$ & $\begin{array}{l}2.3 \\
3.0 \\
1.7\end{array}$ \\
\hline $\begin{array}{l}\text { Secondary school (mean) } \\
\text { Teacher's room }\end{array}$ & 7 & $\begin{array}{l}9.5 \\
9.5\end{array}$ \\
\hline $\begin{array}{l}\text { Hospitals (mean) } \\
\text { Hospital B, newborns inpatients } \\
\text { Hospital B, paediatric outpatients } \\
\text { Hospital Af, emergency department } \\
\text { Hospital A, radiography department (emergencies) }\end{array}$ & $\begin{array}{r}7 \\
11 \\
7 \\
7\end{array}$ & $\begin{array}{l}0.7 \\
0.0 \\
0.2 \\
1.0 \\
1.6\end{array}$ \\
\hline $\begin{array}{l}\text { General practice (mean) } \\
\text { Doctor's room } \\
\text { Stairs }\end{array}$ & $\begin{array}{l}7 \\
7\end{array}$ & $\begin{array}{l}1.1 \\
2.0 \\
0.4\end{array}$ \\
\hline $\begin{array}{l}\text { Public health centre (mean) } \\
\text { Room }\end{array}$ & 12 & $\begin{array}{l}3.7 \\
3.7\end{array}$ \\
\hline $\begin{array}{l}\text { Households, non-smokers (mean) } \\
\text { House A, living room } 1 \\
\text { House B, living room } 2 \\
\text { House B, bedroom }\end{array}$ & $\begin{array}{l}9 \\
8 \\
8\end{array}$ & $\begin{array}{l}0.0 \\
0.0 \\
0.0 \\
0.0\end{array}$ \\
\hline $\begin{array}{l}\text { Households, smokers (mean) } \\
\text { House C, living room }\end{array}$ & 7 & $\begin{array}{l}7.9 \\
7.9\end{array}$ \\
\hline
\end{tabular}

* The monitors were left exposed for 24 hours a day.

$\dagger$ All connections where measures were taken from corresponded to different sites.

$\ddagger$ The same hospital where the canteen's measurement were taken from.

were found to be double those found in a smoker's household. Other studies have shown higher concentrations of nicotine in workplaces, including restaurants, as compared to smokers' homes ${ }^{6-8}$. Our measurements are consistent with and even higher than those found in other studies where mean concentrations ranged from $2-6 \mu \mathrm{g} / \mathrm{m}^{3}$ in offices and from $3-8 \mu \mathrm{g} / \mathrm{m}^{3}$ in restaurants.

Since all areas in our study were sampled 24 hours a day for at least a full week, concentrations were probably much higher during time of occupancy - that is, when non-smokers, especially children, were exposed. The fact that collection of data was made during the winter means that the results may have been less influenced by open windows. The finding of lower concentrations of nicotine in health centres and medical schools, where several local policies are being put in place, is encouraging

The results of this study are intended to raise awareness of involuntary exposure to ETS and the need to enforce compliance with legislation. Such legislation already exists in Catalonia, affecting the public transport system, health and education centres, and large department stores, where smoking is not allowed except in designated areas. ${ }^{9}$ Smokefree policies not only protect non-smokers from second hand smoke, they also create an environment that makes it easier for smokers to stop.

M Jané, M Nebot, $X$ Rojano, L Artazcoz Institut Municipal de Salut Pública, Barcelona Spain J Sunyer ó Mèdica, Barcelona

E Fernández Institut Català d'Oncologia, Barcelona

M Ceraso, J Samet Johns Hopkins Bloomberg School of Public Health, Baltimore, Maryland, USA 
S K Hammond School of Public Health, University of California Berkeley, California, USA

Correspondence to: Manel Nebot Institut Municipal de Salut Pública, Plaça Lesseps 1, 08023 Barcelona, Spain; mneboł@imsb.bcn.es/ bexsa@readysoft.es

\section{Acknowledgements}

We especially wish to thank Charles Perrino and Pablo Villegas from the School of Public Health, University of California, Berkeley, and the Institute for Global Tobacco Control at the Johns Hopkins School of Public Health, Baltimore, for its support in carrying out this study.

\section{References \\ 1 US Environmental Protection Agency. Respiratory health effects of passive smoking: lung cancer and other disorders. Washington DC: Office of Health and Environmental Assessment, 1992. (Publication No EPA/600/6-90/006F.) \\ 2 Kreuzer M, Krauss M, Kreienbrock L, et al. Environmental tobacco smoke and lung cancer: a case-control study in Germany. Am Epidemiol 2000;151:241-50. \\ 3 Hackshaw A, Law $M$, Wald N. The accumulated evidence on lung cancer and environmental tobacco smoke. $B M$ 1997:315:980-8. \\ 4 Hammond SK, Leaderer BP. A diffusion monitor to measure exposure to passive smoking. Environ Sci Technol 1987;21:494-7. \\ 5 Leaderer BP, Hammond SK. Evaluation of vapor-phase nicotine and respirable suspended particle mass as markers for Environmental Tobacco Smoke. Environ Sci Technol 1991;25:770-7. \\ 6 Siegel M. Involuntary smoking in the restaurant workplace. JAMA 1993;270:490-3. \\ 7 Chapman S. Smoking in public places. BM 1996:312:1051-2. \\ 8 Hammond SK. Exposure of US workers to environmental tobacco smoke. Environ Health Perspect 1999;107:329-40. \\ 9 Llei 10/1991, de 10 de maig, de modificacio de la llei 20/1985 de prevencio i assistencia en materia de substancies que poden generar dependencia. DOGC num.1445, maig 1991 [Law restricting smoking in Catalonia].}

\section{A smoking cessation telephone resource: feasibility and preliminary evidence on the effect on health care provider adherence to smoking cessation guidelines}

Physicians have frequent opportunities to ntervene with their smoking patients as approximately $70 \%$ of smokers see a physician each year. ${ }^{1}$ Even brief counselling by a physician significantly improves the rate of smoking cessation according to metaanalyses performed by the Tobacco Use and Dependence Guideline Panel and summarised as "ask, advise, assist, and arrange follow-up" in the Agency for Health Care Policy and Research (AHCPR) guidelines. ${ }^{2}$ Despite these evidence based recommendations, physicians dentify only about half of current smokers, advise less than half, and assist and arrange follow up with a small minority. ${ }^{3}$ There are several explanations for this disparity between physicians' knowledge and their actual behaviour including inadequate training, resource and time constraints, and lack of information on community cessation resources.

Office systems that screen patients for smoking status increase the rate of smoking

Table 1 Adherence of health care providers to smoking cessation interventions

\begin{tabular}{lcll}
\hline Intervention & $\begin{array}{l}\text { Baseline } \\
(\mathrm{n}=54)\end{array}$ & $\begin{array}{l}\text { Post-implementation } \\
(\mathrm{n}=111)\end{array}$ & $\begin{array}{l}\text { Relative risk } \\
\text { Post-implementation } v \\
\text { baseline (95\% Cl) }\end{array}$ \\
\hline Asked & $37(69 \%)$ & $71(64 \%)$ & $0.9(0.7$ to 1.2$)$ \\
Advised to quit & $29(55 \%)^{*}$ & $65(59 \%)$ & $1.1(0.8$ to 1.4$)$ \\
Quit date discussed & $5(9 \%)$ & $14(13 \%)$ & $1.4(0.5$ to 3.6$)$ \\
Assistance offered & $14(26 \%)$ & $46(41 \%) \dagger$ & $1.6(1.0$ to 2.6$)$ \\
Follow up arranged & $9(17 \%)$ & $38(34 \%) \neq$ & $2.1(1.1$ to 3.9$)$ \\
\hline
\end{tabular}

*One subject's data missing for this item, $n=53$.

$\dagger \mathrm{p}=0.052$ versus baseline.

$\neq \mathrm{p}<0.02$ versus baseline.

$\mathrm{Cl}$, confidence interval

cessation interventions by health care providers. ${ }^{4}$ We hypothesised that providers would be more likely to adhere to the AHCPR guidelines if they could delegate the time consuming steps of assistance and follow up to a telephone cessation resource.

This pilot study assessed the feasibility of a central telephone smoking cessation resource that would proactively call smokers who gave their provider consent for referral. We also evaluated whether providers would be then more likely to adhere to the smoking cessation guidelines. In a quasi-experimental pretest, post-test design, a sample of patients seen for any type of visit with a provider in three participating primary care clinics in Vermont were interviewed at exit from the clinic Only current smokers were asked about their providers' adherence to guidelines. The primary outcome measure was the proportion of current smokers who reported being asked advised, assisted, and having follow up arranged at baseline and four months after implementation of the resource.

Two hundred and nine patients were referred to the resource from the three clinics over the four month duration of resource availability. We estimated that this represented $20 \%$ of the total number of smokers seen at the clinics during this time period. We interviewed 54 smokers at baseline and 111 smokers four months after implementation. After the intervention, rates of asking and advising about smoking were not significantly changed from baseline (table 1). The increase in the proportion of smokers who were offered assistance did not reach significance $(\mathrm{p}=0.052)$. There was a significant increase in those who had follow-up arranged (table 1).

Our study demonstrates that a smoking cessation proactive telephone resource is feasible and that providers will refer patients to such a resource. The resource had a contact rate of only $52 \%$ of referred current smokers, which we attribute to the resource not having evening calling hours, a significant limitation. Implementation of this proactive smoking cessation telephone resource was associated with improved arrangement of follow up. These preliminary data suggest that further studies of the effect of referral resources on adherence of physicians to guidelines are warranted. Because of the non-randomised design of this pilot study, we cannot attribute improvements in provider adherence solely to the availability of the telephone resource, as provider focus groups, surveys, and training also may have increased adherence to the guidelines. Only a randomised study can address this issue.
T W Marcy

National Cancer Institute, Division of Cancer Prevention, Office of Preventive Oncology, Rockville, Maryland; Office of Health Promotion Research, University of Vermont College of Medicine, Burlington, Vermont; Vermont Cancer Center, University of Vermont, Vermont USA twmarcy@together.net

L J Solomon

Vermont Cancer Center, and Department of Psychology, University of Vermont

G S Dana, R Secker-Walker

Office of Health Promotion Research, University of Vermont College of Medicine, Burlington, and Vermont Cancer Center, University of Vermont

J M Skelly

Biometry Facility, University of Vermont

\section{Acknowledgements}

Financial support: Robert Wood Johnson Foundation, Princeton, New Jersey (Award 035850), University of Vermont Patient Oriented Research (Award 6-28529)

\section{References}

I Davis R. Uniting physicians against smoking: the need for a coordinated national strategy. JAMA 1988;259:2900-1.

2 Fiore M, Bailey W, Cohen S, et al. Treating tobacco use and dependence. Rockville, Maryland: US Department of Health and Human Services. Public Health Service, 2000

3 Goldstein M, Niaura R, Willey-Lessne C, et al. Physicians counseling smokers: a population-based survey of patients' perceptions of health care provider-delivered smoking cessation interventions. Arch Intern Med 1997;157:1313-19.

4 Fiore $\mathbf{M}$, Jorenby D, Schensky A, et al. Smoking status as the new vital sign: effect on assessment and intervention in patients who smoke. Mayo Clin Proc 1995;70:209-13.

\section{Ophthalmologists' and} optometrists' attitudes and behaviours regarding tobacco cessation intervention

Although health care providers can be effective in motivating and helping patients to quit their tobacco use, ${ }^{1-7}$ the potential role of eye care professionals has been under recognised Several chronic ocular diseases are associated with smoking, ${ }^{8}$ including formation of cataracts and age related macular degeneration (a leading cause of blindness). ${ }^{89}$ As a cardiovascular risk factor, smoking may also play a role in the development of anterior ischaemic optic neuropathy..$^{10}$ In addition, smoking may increase the risk of ocular disease from other disorders, such as diabetes, the main cause of blindness in persons 20-74 years of age. ${ }^{1}$ 
Table 1 Eye care professionals' attitudes, beliefs, and perceived barriers regarding intervention with tobacco using patients

\begin{tabular}{|c|c|c|}
\hline & $\begin{array}{l}\text { Ophthalmologists } \\
(\mathrm{n}=422)(\%)\end{array}$ & $\begin{array}{l}\text { Optometrists } \\
(\mathrm{n}=629)(\%)\end{array}$ \\
\hline \multicolumn{3}{|l|}{ Demographics } \\
\hline Years in practice & 23 (SD 11.33) & 16 (SD 11.23 ) \\
\hline Sex & $85 \%$ male & $72 \%$ male \\
\hline \multicolumn{3}{|l|}{ Tobacco related behaviours: "How often do you ...." } \\
\hline Ask patients about tobacco use? & 71 & 38 \\
\hline Sometimes advise patients to quit tobacco? & 91 & 81 \\
\hline Regularly advise patients to quit tobacco? & 30 & 16 \\
\hline $\begin{array}{l}\text { Provide educational materials on the ocular effects of } \\
\text { tobacco use? }\end{array}$ & 5 & 6 \\
\hline \multicolumn{3}{|l|}{ Barriers to intervening with smokers } \\
\hline Lack of time & 83 & 70 \\
\hline Lack of patient materials & 67 & 79 \\
\hline Lack of training & 64 & 78 \\
\hline Lack of referral resources & 63 & 76 \\
\hline Concerns about effectiveness & 63 & 69 \\
\hline Concerns about patient resistance or loss & 61 & 72 \\
\hline Lack of reimbursement mechanism & 57 & 52 \\
\hline Concerns about office staff resistance & 32 & 40 \\
\hline \multicolumn{3}{|l|}{ Attitudes about intervening with smokers } \\
\hline $\begin{array}{l}\text { Believe it is appropriate for them to document patients' } \\
\text { tobacco use }\end{array}$ & 81 & 69 \\
\hline $\begin{array}{l}\text { Believe it is appropriate for them to advise patients to } \\
\text { quit tobacco }\end{array}$ & 82 & 71 \\
\hline $\begin{array}{l}\text { Interested in learning new ways to help patients quit } \\
\text { tobacco }\end{array}$ & 74 & 80 \\
\hline
\end{tabular}

Before developing a tobacco cessation intervention for eye care professionals, it is essential to assess the current status of tobacco cessation activities in routine eye care. We sent 12 item questionnaire to all currently licensed ophthalmologists $(n=1209)$ and a random sample of 1234 optometrists in four western states of the USA (Arizona, California, Oregon, and Washington), assessing demographics and behaviours, attitudes, and barriers regarding intervention with tobacco using patients. The final return rate was 39\% for ophthalmologists and 53\% for optometrists. Data are presented only for those in current practice $190 \%$ of the ophthalmologists and 95\% of the optometrists). Since ophthalmologists were significantly less likely to return the survey $\left(\chi^{2}(1, n=2443)=48.56, p<0.001\right)$ than optometrists, we report data for each professional group separately without comparing the two.

As table 1 indicates, both ophthalmologists and optometrists feel it is appropriate to help tobacco using patients with cessation, though few do so regularly and many barriers are perceived. Optometrists employing support staff were more likely to express positive attitudes towards providing tobacco interventions than those who did not $(\mathrm{t}(634)=2.55$, $\mathrm{p}<0.05)$, suggesting a correlation between time constraints and attitude toward intervention.

Both ophthalmologists and optometrists cited many barriers to intervening with their tobacco using patients. Lack of time was most commonly cited by ophthalmologists, whereas optometrists were more concerned about lack of patient materials and lack of training. How recently they trained and their sex were related to barriers. Ophthalmologists and optometrists who had graduated more recently from their programmes perceived fewer barriers to providing cessation services $(r=0.18, \quad \mathrm{p}<0.01$ for ophthalmologists; $r=0.16, \mathrm{p}<0.01$ for optometrists). Previous studies $^{112}$ have shown a reduction in perception of barriers due to receiving education in tobacco cessation intervention.

Surprisingly, female ophthalmologists were less likely to believe they should advise patients to quit $(\mathrm{t}(381)=2.16, \mathrm{p}<0.05)$, and both female ophthalmologists and optometrists perceived more barriers to doing so $(\mathrm{t}(365)=-2.54, \mathrm{p}<0.05$ for ophthalmologists, $\mathrm{t}(586)=-2.93, \mathrm{p}<0.01$ for optometrists). This reluctance may be due to female eye care providers' concerns about possible negative patient reactions, or fears of losing patients from their practices.

Although this is a convenience sample, our results suggest the feasibility of brief, office based tobacco cessation interventions for use in eye care settings. An intervention must, however, focus on reducing perceived barriers by training eye care professionals in providing an effective, brief intervention that is readily received by patients, as well as providing resources and materials to practitioners. Our data suggest that cooperative agreements with insurance companies to provide reimbursement to providers would facilitate the adoption of the intervention.

As summarised by the Clinical Practice Guidelines, ${ }^{2}$ many types of general and specialist providers have successfully incorporated tobacco cessation activities into their practices. One way to extend the reach of tobacco cessation interventions is to utilise other medical specialists to motivate tobacco users to quit. Ophthalmology and optometry may provide such an opportunity, given the role of smoking in ocular disease, the fact that most visits are for routine rather than acute care, and the presence of support staff who can help implement an intervention.

J S Gordon
J A Andrews
E Lichtenstein
H H Severson
L Akers
C Williams
1715 Franklin
gon 97403, USA
Dr Judith Gordon;
judith@ori.org

Acknowledgement

Work supported in part by grant R01 CA71018 from the National Cancer Institute.

\section{References}

1 Andrews JA, Severson $\mathrm{HH}$, Lichtenstein E, et al. Evaluation of a dental office tobacco cessation program: effects on smokeless tobacco use Ann Behav Med 1999;21:48-53.

2 Fiore MC, Bailey WC, Cohen SJ, et al Treating tobacco use and dependence. Clinical Practice Guideline. Rockville, Maryland: US Department of Health and Human Services. Public Health Service, 2000

3 Hollis JF, Lichtenstein E, Vogt TM, et al. Hollis JF, Lichtenstein E, Vogt TM, et al.
Nurse-assisted counseling for smokers in primary care. Ann Intern Med 1993; 1 18:521-5.

4 Little SJ, Stevens VJ, Severson HH, et al. An effective smokeless tobacco intervention for dental hygiene patients. J Dental Hygiene 1992;66:185-90.

5 Severson HH, Andrews JA, Lichtenstein E, et al. Reducing maternal smoking and relapse: long-term evaluation of a pediatric intervention. Prev Med 1997;26:120-30.

6 Severson $\mathrm{HH}$, Andrews JA, Lichtenstein E, et al. Using the hygiene visit to deliver a tobacco cessation program: results of a randomized clinical trial. J Am Dental Assoc 1998; 129:993-9.

7 Wall MA, Severson HH, Andrews JA, et al. Pediatric office based smoking intervention: impact on maternal smoking and relapse. Pediatrics 1995;96:622-8.

8 Solberg Y, Rosner M, Belkin M. The association between cigarette smoking and ocular diseases. Survey of Ophthalmology 1998:42:535-47.

9 West S, Munoz B, Emmett EA, et al. Cigarette smoking and risk of nuclear cataracts. Arch Ophthalmol 1989:107: 1 166-9.

10 Margulies LJ. Ocular manifestations of cardiovascular and hematologic disorders. Curr Opin Ophthalmol 1995;6:97-103.

11 Alexander LJ, Duenas MR. Eye care for patients with diabetes in the state of Florida: status in 1988. J Am Optometric Assoc 1994;65:552-8.

12 Gordon JS, Severson HH. Tobacco cessation through dental office settings. J Dent Educ $2001 ; 65: 354-63$.

\section{CORRECTION}

The authors of Health impact of "reduced yield" cigarettes: a critical assessment of the epidemiological evidence (Tobacco Control 2001;10(suppl I):i4-il l) would like to correct a statement in figure 1 . The legend to figure 1 and the corresponding text on page 15 should say "Each milligram decrease in machine measured nicotine..." rather than "Each milligram decrease in machine measured tar...". 